\title{
ELOGIO DEL PROF. ALBERTO PORTERA SÁNCHEZ
}

Vicente Calatayud Maldonado

Académico de Número de la Real Academia Nacional de Medicina de España- Neurocirugía

Excmo. Sr. Presidente de la RANME. Excmos. e Ilmos. Sras. y Sres. Académicos. Familiares del Prof. Alberto Portera.

El día 30 del próximo noviembre hará un año que nos dejó nuestro compañero Alberto Portera. Académico, nacido en Caspe, Ciudad del Compromiso, y, como neurólogo científico, reconocido internacionalmente al definir una novedosa forma de entender las neurociencias.

Si nadie discute sus decisivas aportaciones al progreso del saber, acaso sea menos conocida su constante preocupación por acercar el conocimiento científico, y la neurociencia en particular, a la sociedad, especialmente a través del arte. Todo ello unido a su audacia, casi osadía, y a su esfuerzo continuado frente a las enfermedades degenerativas del Sistema Nervioso.

Alberto Portera fue una de esas personas singulares en la que se unían la bondad y la sabiduría, que no siempre andan juntas. Este gran hombre -que también era un hombre grande, de casi $1.90 \mathrm{~m}$ de altura-, albergaba en su gran envergadura material un temperamento firme y un carácter sin recovecos. Firmeza inteligente, embridada por la templanza y adobada con una ironía brillante, manejada con soltura y gracejo. Era un intelectual e influía en los demás. Daba criterio. Poseía una inteligencia clara y una capacidad didáctica reconocida por gran número de alumnos y discípulos que recibieron sus enseñanzas clínicas, pero también artísticas y deportivas.

Atraía asimismo por su enciclopédica cultura, nada superficial, sino muy bien cimentada: música, literatura, arte, cine, teatro, toros... Pocos ámbitos de interés escapaban a su análisis, certero y apasionado a la vez. No se cansaba de examinar críticamente cualquier diseño o proyecto y era un duro contrincante en el debate, porque siempre acompañaba la crítica con buenos argumentos, de los que resultan difíciles de rebatir.

Y fue un gran y constante defensor, en todo tiempo y momento, de los valores de su tierra y de la gente nacida en Aragón.

Alberto era un sabio, un gran sabio, y, como tal, humilde, cercano, afectuoso, divertido y generosísimo con todo el mundo, en especial con sus alumnos, para los que desveló algunas de las incógnitas que se construyen y encierran en el cerebro. Y, de modo particular, las bases neurales de la producción artística y de la creatividad.

Como gran innovador, le retaba, en un desafío fascinante, el llegar a comprender las relaciones entre los sustratos biológicos del cerebro y las construcciones filosóficas de la mente.

Pero, sobre todo y más que nada, Alberto Portera Sánchez poseía, como ejemplo acabado de médico humanista, una rara sagacidad para comprender y ayudar a los seres humanos durante sus episodios de lucha y vulnerabilidad. Siempre mantuvo en primer plano la relación médico-paciente: la usó en beneficio del enfermo y de nuestro Arte y nos la legó con su ejemplo como un rico tesoro que, para qué engañarnos, hoy corre peligro entre nosotros.

Quienes hoy practican la Medicina cimentándola, como debe ser, en el primum non nocere, harían bien en imitar a Alberto y recorrer tras sus pasos la senda del mejor saber médico, guiándose por la conciencia de humanidad y por la virtud de la compasión, para ayudar y apoyar a quienes están en mayor necesidad. Gracias, amigo querido. Descansa en paz.

\section{DECLARACIÓN DE TRANSPARENCIA}

El autor/a de este artículo declara no tener ningún tipo de conflicto de intereses respecto a lo expuesto en el presente trabajo.

Si desea citar nuestro artículo:

Calatayud Maldonado V. Elogio del Prof. Alberto Portera Sánchez. An RANM. 2021;138(01).supl01: 24. D0I: 10.32440/ ar.2021.138.01.supl01.art05

\section{Autor para la correspondencia}

